\title{
What Matters in Artificial Learning, Sonority Hierarchy or Natural Classes?
}

\author{
Yu-Leng Lin \\ University of Toronto
}

\section{Introduction}

In recent years, questions have been raised in linguistics about just what properties of grammar are universal and what emerges through exposure to language (Blevins 2004, 2006, Moreton 2008, Botma 2011, Mielke 2011, Parker 2008, Parker 2011 among others). In this paper, I address a particular aspect of this issue, focusing on the susceptibility of segments of different types to nasalization. More particularly, the study examines the nasalized segment constraint hierarchy, *nasalized plosive $>$ *nasalized fricative >> *nasalized liquid > *nasalized glide > *nasalized laryngeal > *nasalized vowel proposed by Walker (2000), concentrating on the relationship between targets and blockers of nasal harmony.

Nasal harmony is cross-linguistically common (a local process where a nasal trigger spreads the feature [nasal] rightward or leftward, stops when it encounters a blocker, see Walker 2011), but still insufficiently understood. The nasalized segment constraint hierarchy is generally considered to be related to sonority, with a more sonorant segment more likely to be nasalized, and with a less sonorant segment being nasalized in nasal harmony only if more sonorant segments are. There is a debate about the status of the sonority scale, with some arguing that it is phonological (e.g., Hooper 1976, Clements 1990, Blevins 1995, Zec 2007), and others arguing that it is a consequence of phonetic correlates, and epiphenomenal (e.g., Gordon 1999, Henke et al. 2012, Evans \& Levinson 2009, Daland et al. 2011).

One reason for considering the sonority hierarchy to be phonological is that there are some differences between languages in how particular segments interact in terms of sonority but the sonority hierarchy of different languages all follow the same tendency (least sonorant to more sonorant). For instance, one language might have a consonant sonority hierarchy as follows, from least to most sonorant: voiceless stops $>$ voiced stops $>$ voiceless fricatives $>$ voiced fricatives $>$ nasals $>$ liquids $>$ glides, while another language might have a relatively simplified consonant sonority hierarchy: stops $>$ fricatives $>$ nasals $>$ liquids $>$ glides (e.g., Prince \& Smolensky 1993, de Lacy 2000, Smith 2002, Parker 2002, de Lacy 2006). Even within obstruents, Clements (1990) among others argues that languages can differ in whether obstruents are treated as a class or are more finely differentiated. In addition, certain segments may pattern as part of different classes- /v/ patterns as a fricative in some languages and as a sonorant in others. Such differences in sonority suggest a phonological account because such an account entails that sonority is active in phonological patterning. In addition to patterning, sonority plays a similar role in various phonological phenomena cross-linguistically such as phonotactic constraints (e.g., consonant clusters, syllabification-vowel epenthesis, deletion, syllabic consonants, metathesis) and morphophonemic alternations (lenition, fortition) (see Parker 2002, Cser 2003, Honeybone 2008, Parker 2011).

If the sonority hierarchy is phonological, further questions arise: how much is universal (built-in), and how much is language-specific (emerging from language acquisition)? If a more fine-grained sonority hierarchy has to emerge from exposure, why are sonority effects so robust cross linguistically? Why do languages that have reverse sonority hierarchy effects not occur typologically? Assuming the nasal hierarchy mirrors the sonority hierarchy, where does nasal harmony come from?

This study aims to tackle the above issues, and contributes to a better understanding of the interaction between nasal harmony with opaque segments and learnability.

\footnotetext{
* Thanks Keren Rice, Yoonjung Kang, and Alexei Kochetov for their suggestions and feedback. Thanks for Sara Finley's feedback. This project is supported by SIG 2014-2015, University of Toronto.

(C) 2016 Yu-Leng Lin

Proceedings of $A M P 2015$

Completed March 26, 2016
} 
In recent phonological research, an artificial grammar (AG) paradigm (e.g., Moreton \& Pater $2012 \mathrm{a}, \mathrm{b}$, Finley 2011, Nevins 2010, Moreton 2008, Wilson 2006) has been used to test language universals. This paradigm allows the study of aspects of proposed universals that can be hard to test with real language. My research examines one proposed universal, the implicational nasal hierarchy scale, testing whether this scale is found with speakers of a language with no clear evidence for a nasal hierarchy.

Walker (2011) proposes a universal implicational nasalized segment scale based on evidence from typological frequency, Vowels $>$ Glides $>$ Liquids $>$ Fricatives $>$ Stops. She argues that if a more marked blocker class blocks harmony (vowels are least marked targets, so least likely to be blockers, and most likely to be targets), so do the less marked blocker classes (stops are most marked targets, so most likely to be blockers, and least likely to be targets). I address whether a pattern that is predicted by this implicational universal is easier to learn than one that is not. In particular, I investigate if it is easier to make a generalization when a more marked blocker (vowel)/target (stop) is presented during training and a less marked blocker (stop)/target (vowel) in testing rather than vice versa.

\section{Experiment}

In the experiments, different groups were presented with the four patterns as in Table 1. For instance, for Pattern 1, if a listener/learner is introduced to a system showing nasal harmony involving a sound like /s/ as a target ("old-same class") and then is asked whether a sound like /w/ (different phonological class, "newgeneralizable") will be nasalized, the answer should be yes, since fricative $/ \mathrm{s} /$ is a more marked target class with respect to the hierarchy than glide /w/ target class. On the other hand, for Pattern 2, if the listener/learner is exposed to a sound like /w/ as a target and is asked whether a sound like /s/ will be nasalized, there is no real way of knowing, since /w/ is less marked than /s/ (target classes) with respect to the hierarchy. Thus exposure to $/ \mathrm{s} /$ as a target predicts the targeting of $/ \mathrm{w} /$ but exposure to $/ \mathrm{w} /$ as a target does not predict the targeting of $/ \mathrm{s} / . / \mathrm{k} /$ in both Patterns 1 and 2 is a blocker in both exposure and test phases (Pattern 1: abbreviated as $\mathrm{S}(\mathrm{k}) \rightarrow \mathrm{W}(\mathrm{k})$, Pattern 2: abbreviated as $\mathrm{W}(\mathrm{k}) \rightarrow \mathrm{S}(\mathrm{k})$, capital letters stand for targets, a segment in brackets means that it is present in both familiarization and test phases). The predictions are based on expectations if the nasal hierarchy is universal: it should be easier to learn a grammar if in the test phase the new segment is more sonorant than the target (cf. Pattern 1) or equivalent in sonority to the blocker (cf. Patterns 3,4) in the exposure phase. If the test segment is less sonorant than the target (cf. Pattern 2), then there is essentially no prediction.

A critical prediction then is that what I call "direction" is important: exposure to a less sonorant target makes predictions about the treatment of a more sonorant sound, but exposure to a more sonorant target makes no predictions about the treatment of a less sonorant sound.

Table 1. Four patterns

\begin{tabular}{|c|c|c|c|}
\hline & exposure & test & prediction \\
\hline $\begin{array}{l}\text { Pattern } 1 \\
\mathrm{~S}(\mathrm{k}) \rightarrow \\
\mathrm{W}(\mathrm{k})\end{array}$ & $\begin{array}{l}\text { more sonorant: target } / \mathrm{s} / \\
\text { less sonorant: blocker } / \mathrm{k} /\end{array}$ & $\begin{array}{l}\text { new segment } / \mathbf{w} / \text { : } \\
\text { more sonorant than target }\end{array}$ & new segment is a target \\
\hline $\begin{array}{l}\text { Pattern } 2 \\
\mathrm{~W}(\mathrm{k}) \rightarrow \\
\mathrm{S}(\mathrm{k})\end{array}$ & $\begin{array}{l}\text { more sonorant: target } / \mathrm{w} / \\
\text { less sonorant: blocker } / \mathrm{k} /\end{array}$ & $\begin{array}{l}\text { new segment } / \mathbf{s} / \text { : } \\
\text { less sonorant than target }\end{array}$ & no prediction \\
\hline $\begin{array}{l}\text { Pattern } 3 \\
\mathrm{k}(\mathrm{S}) \rightarrow \mathrm{t}(\mathrm{S})\end{array}$ & $\begin{array}{l}\text { more sonorant: target } / \mathrm{s} / \\
\text { less sonorant: blocker } / \mathbf{k} /\end{array}$ & $\begin{array}{l}\text { new segment } / \mathbf{t} /: \\
\text { same class as blocker }\end{array}$ & new segment is blocker \\
\hline $\begin{array}{l}\text { Pattern } 4 \\
\mathrm{k}(\mathrm{W}) \rightarrow \\
\mathrm{t}(\mathrm{W})\end{array}$ & $\begin{array}{l}\text { more sonorant: target /w/ } \\
\text { less sonorant: blocker } / \mathbf{k} /\end{array}$ & $\begin{array}{l}\text { new segment } / \mathbf{t} / \text { : } \\
\text { same class as blocker }\end{array}$ & new segment is blocker \\
\hline
\end{tabular}




\section{Methods}

3.1 Design The experiment included a familiarization phase, a test phase, and a post-test ${ }^{1}$. Participants were exposed to pairs of morphologically related items with a singular form and a plural form. This morphophonemic design has been extensively used in phonological artificial grammar learning (Kapatsinski 2009, Albright \& Do 2013 among others). The singular form was composed of oral segments. In the plural, the first vowel was nasalized and, depending on the intervening consonants, subsequent vowels could be nasalized as well.

Words were of the structure $\mathrm{V}_{1} \cdot \mathrm{C}_{2} \mathrm{~V}_{2} \cdot \mathrm{C}_{3} \mathrm{~V}_{3}$, where $\mathrm{V}_{1}$ was oral in the singular forms (e.g., /asawa/) and nasal in the plural forms (e.g., /ãsawa/). $\mathrm{C}_{2}$ and $\mathrm{C}_{3}$ varied between targets and blockers. [nasal] on $\mathrm{V}_{1}$ would spread rightward to $V_{2}$ and $V_{3}$ if there was no blocker interfering (e.g., /ãwãã $\left.\tilde{a} /\right)$. Syllable structures conformed to the phonotactics of Min. The lexical monosyllables in Min.

Four groups of artificial grammars (four patterns) were generated. Note that throughout this paper, I use the underlying representation instead of the surface representation to indicate nasal harmony, even though it is difficult to find nasal flow on obstruents (e.g., /k, s/ used for the current study) phonetically and is likely impossible for them to be nasalized acoustically or articulatorily (see Boersma 1998, 2003 for discussion). This notation simply shows that they are transparent to nasal harmony.

For the four groups, $\mathrm{V}_{1}$ was /a/ (singular) or /ã/ (plural) (e.g., singular: /awasa/ vs. plural: /ãw̃ãsa/). The direction of nasal harmony for plural forms was always from left to right (triggered by a plural morpheme [nasal] on $\mathrm{V}_{1}$ ). Note that although in real languages, the trigger is not necessarily in the first syllable, in the experiments reported in this paper, the trigger was always in the first syllable. The reason for this is that if the trigger varied in position, the span of nasal harmony would become more narrowed, which would make it more difficult to see a crucial nasality interaction among vowels, glides, fricatives and oral stops.

During the familiarization phase, participants listened to a singular form (e.g. $\mathrm{S}(\mathrm{k}) \rightarrow \mathrm{W}(\mathrm{k})$ : /akasa/), and then a corresponding plural form (e.g., $\mathrm{S}(\mathrm{k}) \rightarrow \mathrm{W}(\mathrm{k})$ : /ãkasa/). Take $\mathrm{S}(\mathrm{k}) \rightarrow \mathrm{W}(\mathrm{k})$ for instance. $/ \mathrm{k} /$ was a blocker, /s/ was a target, and nasality on /a/ served as a plural marker, triggering nasal spreading rightward. The logical combinations used in the familiarization are four (V.CV.CV) in (1):

(1) Four combinations of items in the familiarization phase (singular $\mid$ plural)

(a) trigger + blocker + vowel + target + vowel /akasa/ |/ãkasa/

(b) trigger + target + vowel + blocker + vowel /asaka/ | /ã̃̃ãka/

(c) trigger + blocker + vowel + blocker + vowel /akaka/ | /ãkaka/

(d) trigger + target + vowel + target + vowel /asasa/ | /ã̃̃ãs̃a /

16 familiarization sets for Patterns 1 and 2 were generated separately. The familiarization sets in the familiarization phase for (a) and (c) were repeated three times in three different blocks, while (b) and (d) were repeated six times in three different blocks in an attempt to increase participants' exposure to crucial combinations with changes in nasalization.

The test items are presented in Table 2. Each trial was orally presented to participants. During the test phase, they were shown a singular form first (e.g., $\mathrm{S}(\mathrm{k}) \rightarrow \mathrm{W}(\mathrm{k})$ : /asaka/), and then were asked to choose the plural form which obeys the language plural rule from two items (e.g., $\mathrm{S}(\mathrm{k}) \rightarrow \mathrm{W}(\mathrm{k})$ : (1) /ãs̃ãka/ vs. *(1') /ãsaka/). If they thought the first test item was correct, they pressed "1", if they thought the second one was correct, then they pressed " 2 ".

\footnotetext{
${ }^{1}$ A post-test was given to ensure that the participants could hear the distinction between nasalized and oral segments. In this post-test, each participant heard one pair of monosyllables at a time. These were identical to the monosyllables used in the main experiment. The participants had to judge which monosyllable was nasalized. This post-test was done after the main experiment, so that the participants would not get a clue about the role of nasality in the main experiment. Following Lin (2010), the correct rate for passing the post-test was set to 75\%. The participants who failed to distinguish between /a/ and /ã/ were eliminated, since if participants were not able to distinguish trigger from non-trigger, then it is not appropriate to use their data to test for the implicational universal scale.
} 
Table 2. Stimuli design (test items)

\begin{tabular}{|c|c|c|c|c|c|c|}
\hline & \multicolumn{3}{|c|}{ Pattern 1: $\mathbf{S}(\mathbf{k}) \rightarrow \mathbf{W}(\mathbf{k})$} & \multicolumn{3}{|c|}{ Pattern 2: $\mathbf{W}(\mathbf{k}) \rightarrow \mathbf{S}(\mathbf{k})$} \\
\hline & \multicolumn{2}{|c|}{ new } & \multirow{2}{*}{$\begin{array}{c}\text { old } \\
\text { same class } \\
(\mathrm{n}=8, \text { pair }=4)\end{array}$} & \multicolumn{2}{|c|}{ new } & \multirow{2}{*}{$\begin{array}{c}\text { old } \\
\text { same class } \\
(\mathrm{n}=8, \text { pair }=4)\end{array}$} \\
\hline & $\begin{array}{c}\text { gen } \\
(\mathrm{n}=10, \text { pair }=5)\end{array}$ & $\begin{array}{c}\text { same class } \\
(\mathrm{n}=10, \text { pair }=5)\end{array}$ & & $\begin{array}{c}\text { gen } \\
(\mathrm{n}=10, \text { pair }=5)\end{array}$ & $\begin{array}{c}\text { same class } \\
(\mathrm{n}=10, \text { pair }=5)\end{array}$ & \\
\hline $\begin{array}{l}\text { grammatical } \\
(n=44)\end{array}$ & $\begin{array}{l}\text { (10) /ãw̃ãka/ } \\
\text { (11) /ãkawa/ } \\
\text { (12) /ãw̃ãs̃ã/ } \\
\text { (13) /ãw̃ã } \tilde{w} a ̃ / \\
\text { (14) /ãs̃ãw̃ã/ }\end{array}$ & 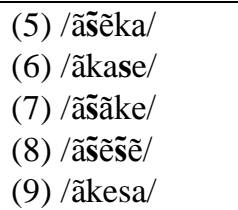 & $\begin{array}{l}\text { (1) /ãs̃ãka/ } \\
\text { (2) /ãkasa/ } \\
\text { (3) /ãs̃ãs̃ã/ } \\
\text { (4) /ãkaka/ }\end{array}$ & 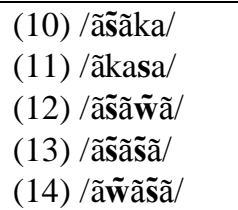 & 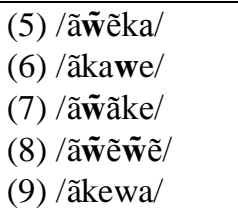 & 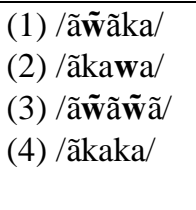 \\
\hline $\begin{array}{l}\text { ungrammatical } \\
(n=44)\end{array}$ & 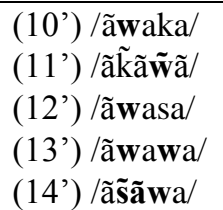 & 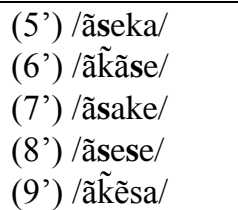 & 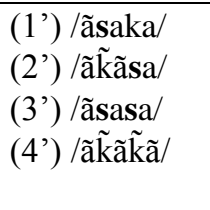 & $\begin{array}{l}\left(10^{\prime}\right) / \text { ãsaka/ } \\
\left(11^{\prime}\right) / \text { ã̃ãããa// } \\
\left(12^{\prime}\right) / \text { ãsawa/ } \\
\left(13^{\prime}\right) / \text { ãsasa/ } \\
\left(14^{\prime}\right) / \text { ãwããsa/ }\end{array}$ & $\begin{array}{l}\left(5^{\prime}\right) / \text { ãweka/ } \\
\left(6^{\prime}\right) / \text { ã̃ãwe/ } \\
(7 ') / \text { ãwake/ } \\
\left(8^{\prime}\right) / \text { /ãwewe/ } \\
(9 ') / \text { ãkẽwa/ }\end{array}$ & $\begin{array}{l}\text { (1') /ãwaka/ } \\
\text { (2') /ã̃ããwa/ } \\
\text { (3') /ãwawa/ } \\
\text { (4') /ã } \tilde{k} \tilde{k} \tilde{k} \tilde{a} /\end{array}$ \\
\hline
\end{tabular}

(gen= generalizable, $\mathrm{n}=$ number $)$

Each pair consists of grammatical (conforming to the pattern) and ungrammatical items. For example, for Pattern 1: $\mathrm{S}(\mathrm{k}) \rightarrow \mathrm{W}(\mathrm{k})$, a participant would hear /ã wãka/ (grammatical), and then /ãwaka/ (ungrammatical). The correct answer should be "1".

Consider the $\mathrm{S}(\mathrm{k}) \rightarrow \mathrm{W}(\mathrm{k})$ pattern. (cf. Table 2). Participants are trained on $/ \mathrm{s} / \mathrm{as}$ a target and tested on whether they treat /w/ as a target. If participants treat /w/ as a target, then they will tend to favor (12) /ãwãka/ over (12') */ãwaka/ and to favor (14) /ãs̃ã⿱wã/ over (14') */ãs̃ãwa/. However, if they treat /w/ as a blocker, then their preference will be the other way around (favoring (12') */ãwaka/ over (12) /ãwãa/ and favoring $\left(14^{\prime}\right) * / a \tilde{a} \tilde{a}$ wa/ over (14) /ãs̃ã $\tilde{a}$ /). Because the test involves a pairwise forced choice, participants have the freedom to determine whether they treat a new segment $/ \mathrm{w} /$ as a target or as a blocker. If there is a bias toward $/ \mathrm{w} /$ as a target, then the hypothesis that participants are able to generalize from $/ \mathrm{s} /$ as a target to $/ \mathrm{w} /$ as a target would receive support. Take $\mathrm{S}(\mathrm{k}) \rightarrow \mathrm{W}(\mathrm{k})$ pattern for instance. Items containing an old consonant $/ \mathrm{s} /$ and an old vowel belong to "old-same (phonological) class". Items containing an old consonant /s/ and a new vowel belong to "new-same class" since it involves a "new' vowel, but the phonological class of the consonant is the same as that of old items (i.e., /s/). Items containing a new consonant /w/ belong to "new-gen" to test generalizability.

I am also interested to see if participants use any strategies to "guess". In items (11) and (11') in Table 2 , if participants think segments should always be nasalized, then I would expect that they would nasalize an old segment $/ \mathrm{k} /$, even though it was not nasalized in the familiarization phase (favoring (11') */ã $\tilde{\text { ã } \tilde{w} a ̃ / / ~ o v e r ~}$ (11) /ãkawa/) $)^{2}$.

For old and new-same class items, the ungrammatical counterparts are just the reversed relationship between targets and blockers. That is, /s/ was a blocker, and $/ \mathrm{k} /$ was a target.

3.2 Stimuli The tri-syllabic nonce-words were created by concatenating syllables spoken in isolation by a male native Min speaker who was naive to the goals of the experiment. The tonal value for each syllable was high level (55), used without any further manipulation. Each 'word' was synthesized individually.

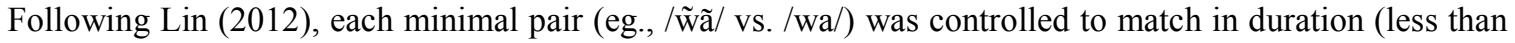
$30 \mathrm{~ms}$ difference), and the durations for the whole 'word' were also controlled (less than $30 \mathrm{~ms}$ difference). Concatenation misses appropriate vowel transitions (F1-F3), which might potentially sound odd. To rule out this concern, the minimal pairs of monosyllables were presented to a trained linguist to make sure each pair was contrastive perceptually. The silence before the first syllable was set to $150 \mathrm{~ms}$, the silence between the first and the second syllable was set to $100 \mathrm{~ms}$, and the silence between the second and third syllable was

2 I use "ungrammatical" to refer to other variations compared to grammatical items (e.g., for Pattern 2, old-same class \& new-same class: /w/ is a blocker, and / $\mathrm{k} /$ is a target. But different from Pattern 2, new-gen was designed in a way that could test different strategy (e.g., /k/ is nasalized, and /s/ is nasalized like (11') */ã $\tilde{k} \tilde{\mathbf{s}} \tilde{a} / ; / \mathrm{w} /$ is a target, and /s/ is a blocker like (12') */ã $\tilde{\mathbf{w} a} \mathbf{s a} / ; / \mathrm{s} /$ is a blocker and / $/ \mathrm{k} /$ is a blocker like (1') */ãsaka/. But since I did not have a prediction on implicational universal about whether the new segment /s/ would be a target or blocker, so technically, I could not refer (12') */ã w̃ãsa/ and (1') */ãsaka/ as "ungrammatical", since both of them are "possible" patterning in nasal harmony. 
also set to $100 \mathrm{~ms}$. No acoustic checkup was involved (e.g., F1-F3 for transition).

3.3 Procedure The experiment was run with E-Prime (Schneider et al. 2002). In the familiarization phase, participants received oral instructions from the experimenter, along with detailed written instructions on the computer screen. The participants first were presented with one of the artificial grammars. The participants were told that they would learn a made-up language that contained tri-syllabic words and they had to search for a singular/plural rule hidden in the familiarization phase. In the familiarization phase, they heard singular and plural forms in pairs. That is, they heard a word accompanied by a picture of one item (e.g., a picture of one apple), pressed the space bar, and then they heard a word accompanied by a picture of two of the same item (e.g., a picture of two apples). When participants heard a word, they were told to pronounce it once as close to the original sounds as possible. They were also informed that only plural forms would change, and singular forms would be treated as base forms. In the test phase, they were told that they would be tested on how well they could learn the singular/plural rule based on a grammaticality judgment test, and that they needed to make a judgment even though certain sounds did not occur in the familiarization phase.

3.4 Participants For each of the patterns, 10 college students were recruited from National Sun Yat-sen University in Taiwan, and were paid 150 NTD for participating in the experiment. All had normal hearing. The rate of distinguishing nasalized monosyllables from their oral counterparts (post-test) was 100\%. All had early childhood exposure to Min. All had studied foreign languages. The mean age is $21.4(\mathrm{SD}=2.4)$.

\section{Results and discussion}

4.1 Group results Test items were analyzed using mixed-effect logistic regression modeling (GLMM) (Pinheiro \& Bates 2000) implemented in the R package lme4 (Bates \& Maechler 2009). "Direction" was -1 for $\mathrm{W}(\mathrm{k}) \rightarrow \mathrm{S}(\mathrm{k})($ Pattern 2), and 1 for Patterns $\mathrm{S}(\mathrm{k}) \rightarrow \mathrm{W}(\mathrm{k})$ (Pattern 1). The logic behind this factor is that if the results support the hypotheses about implicational universals investigated in this study, then it is expected that participants in the $\mathrm{S}(\mathrm{k}) \rightarrow \mathrm{W}(\mathrm{k})$ group should learn better than those in the $\mathrm{W}(\mathrm{k}) \rightarrow \mathrm{S}(\mathrm{k})$ group, because the sonority for $/ \mathrm{s} /$ is lower than that of $/ \mathrm{w} /$. Thus blocking by $/ \mathrm{w} /$ implies blocking by $/ \mathrm{s} /$, but not vice versa. In addition, if $\mathrm{s}$ is a target, this implies that $\mathrm{w}$ is also a target. By this logic, the baseline (i.e., coding:-1) for "Direction" should be $\mathrm{W}(\mathrm{k}) \rightarrow \mathrm{S}(\mathrm{k})$. If we find a significant "positive effect", then it means that $\mathrm{S}(\mathrm{k}) \rightarrow \mathrm{W}(\mathrm{k})$ is learned better than $\mathrm{W}(\mathrm{k}) \rightarrow \mathrm{S}(\mathrm{k})$. This factor is crucial, since it could directly test whether the experimental results support the hypotheses. I arbitrarily coded $\mathrm{k}(\mathrm{W}) \rightarrow \mathrm{t}(\mathrm{W})($ Pattern 4$)$ as -1 , and $\mathrm{k}(\mathrm{S}) \rightarrow \mathrm{t}(\mathrm{S})$ as 1 . It is not expect to find a main effect of "Direction" because both $/ \mathrm{k} /$ and $/ \mathrm{t} /$ belong to stops. The test items had three types: old-same class, new-same class and new-generizable (new-gen), and I coded them as O, NS and NGEN. These three categories were grouped into "TypeName". "TypeName" is to make sure if there is any treatment/manipulation effect such as memory effect.

I compared Pattern 1 with Pattern 2, Pattern 3, and Pattern 4. The logistic regression shows a positive influence of "direction" for Patterns 1 and 2, with testing on a more sonorant segment than learners were exposed to being better learned (Pattern 1: coding as 1) than testing on a less sonorant target (Pattern 2: coding as -1). No main effect of "Direction" was found between Patterns 3 and 4.

4.2 Individual learner types Learners fell into two distinct categories, what I call categorization learners and statistical learners. The former grouped new segments with old segments, while the latter used fragmentary knowledge (e.g., phonotactic information) to determine what served as a blocker and what as a target. I focus on the results for the categorization learners.

Though my hypothesis concerns implicational universals, it is also the case that individuals might vary in their systems. Finley (2011) reported that participants could generalize to an undesired pattern not predicted by her hypothesis. This suggests that individuals might develop different strategies when making their judgments. In this section, I classify participants into different learner types using Patterns 1 and 2 as examples. I propose two major types of learners: what I call categorization learners and statistical learners. "Categorization learner" means that participants tried to group a new segment with certain old segments. Those grouped new segments would share the same role in nasal harmony (i.e., either target or blocker). "Statistical learner" means that participants used fragment knowledge like syllable combinations (e.g., phonotactics) to make a judgment (see discussion of statistical learning in Shaffran 1996, Shaffran et al. 1999, Gomez and Gerken 1999, Fiser and Aslin 2002, Yang 2004 among others). Categorization learners can be further broken down into three subcategories, namely pattern learner, generalizer, and generalizer (opposite). 
"Statistical learners" too can be further broken down into statistician and pluralizer. Note that if participants randomly guess, I refer to them as "random". The predictions of learner types about old-same class for Pattern 1 are shown in Table 3 and for Pattern 2 in Table 4. "Grammatical" items in Pattern 1 conform to the pattern of nasal harmony where $/ \mathrm{s} /$ and vowels are targets and $/ \mathrm{k} /$ is a blocker, whereas "ungrammatical" items are the pattern of nasal harmony where $/ \mathrm{s} /$ is a blocker, and $/ \mathrm{k} /$ and other vowels are targets. For instance, the categorization learners learned the pattern, and judge old grammatical forms $(1,2,3,4)$ as grammatical and ungrammatical forms as ungrammatical $\left(1^{\prime}, 2^{\prime}, 3^{\prime}, 4^{\prime}\right)$. That is, when categorization learners make a judgment on pairs, they would correctly choose grammatical old-same class items (check mark $\checkmark$ in the cell) over ungrammatical items (blank in the cell) ${ }^{3}$. The statistical learners, on the other hand, are sensitive to the positions or numbers of nasalized syllables. The discussion of subtypes follows Table 3 and Table 4.

\subsubsection{Old-same class}

Table 3. Pattern 1: Predictions of raw responses for test items by leaners' types: old-same class

\begin{tabular}{|c|c|c|c|c|c|c|}
\hline & \multicolumn{6}{|c|}{ Pattern 1: $\mathbf{S}(\mathbf{k}) \rightarrow \mathbf{W}(\mathrm{k})$} \\
\hline & & \multicolumn{3}{|c|}{ categorization learner } & \multicolumn{2}{|c|}{ statistical learner } \\
\hline & & $\begin{array}{l}\text { pattern } \\
\text { learner }\end{array}$ & generalizer & $\begin{array}{c}\text { generalizer } \\
\text { (opposite) }\end{array}$ & statistician & $\begin{array}{c}\text { pluralize } \\
\mathrm{r}\end{array}$ \\
\hline & Old-same class & & & & & \\
\hline \multirow[t]{4}{*}{ grammatical } & (1) /ãs̃ãka/ & $\checkmark$ & $\checkmark$ & $\checkmark$ & $\checkmark$ & $\checkmark$ \\
\hline & (2) /ãkasa/ & $\checkmark$ & $\checkmark$ & $\checkmark$ & & \\
\hline & (3) /ã̃̃ã $\tilde{\mathbf{s}} /$ & $\checkmark$ & $\checkmark$ & $\checkmark$ & $\checkmark$ & $\checkmark$ \\
\hline & (4) /ãkaka/ & $\checkmark$ & $\checkmark$ & $\checkmark$ & & \\
\hline \multirow[t]{4}{*}{ ungrammatical } & (1')/ãsaka/ & & & & & \\
\hline & (2')/ã k̃ãsa/ & & & & & $\checkmark$ \\
\hline & (3’) /ãsasa/ & & & & & \\
\hline & (4') /ãk̃ã $\tilde{a} /$ & & & & & $\checkmark$ \\
\hline
\end{tabular}

Table 4. Pattern 2: Predictions of raw responses for test items by leaners' types: old-same class

\begin{tabular}{|c|c|c|c|c|c|c|}
\hline & \multicolumn{6}{|c|}{ Pattern 2: $\mathbf{W}(\mathbf{k}) \rightarrow \mathbf{S}(\mathbf{k})$} \\
\hline & & \multicolumn{3}{|c|}{ categorization learner } & \multicolumn{2}{|c|}{ statistical learner } \\
\hline & & $\begin{array}{l}\text { pattern } \\
\text { learner }\end{array}$ & generalizer & $\begin{array}{c}\text { generalizer } \\
\text { (opposite) }\end{array}$ & statistician & $\begin{array}{c}\text { pluralize } \\
\mathrm{r}\end{array}$ \\
\hline & Old-same class & & & & & \\
\hline \multirow[t]{4}{*}{ grammatical } & (1) /ãw̃̃ãa/ & $\checkmark$ & $\checkmark$ & $\checkmark$ & $\checkmark$ & $\checkmark$ \\
\hline & (2) /ãkawa/ & $\checkmark$ & $\checkmark$ & $\checkmark$ & & \\
\hline & (3) /ã $\tilde{\mathbf{w} a ̃ \tilde{w} a ̃ / / ~}$ & $\checkmark$ & $\checkmark$ & $\checkmark$ & $\checkmark$ & $\checkmark$ \\
\hline & (4) /ãkaka/ & $\checkmark$ & $\checkmark$ & $\checkmark$ & & \\
\hline \multirow[t]{4}{*}{ ungrammatical } & (1')/ãwaka/ & & & & & \\
\hline & (2’) /ã̃ããwa/ & & & & & $\checkmark$ \\
\hline & (3’) /ãwawa/ & & & & & \\
\hline & (4’) /ãk̃ããã/ & & & & & $\checkmark$ \\
\hline
\end{tabular}

Pattern learner means that participants learn the pattern, but fail to generalize from an old target to a new test consonant $(/ \mathrm{w} /$ in Pattern $1, / \mathrm{s} /$ in Pattern 2$)$. If this is the case, I would expect that when choosing a word out of a pair, participants would tend to favor grammatical old-same class $(1,2,3,4)$ over ungrammatical old-same class items (1', 2', 3', 4') (cf. Table 3 and Table 4).

\footnotetext{
${ }^{3}$ The subtypes of categorization learners (i.e., pattern learner, generalizer, opposite generalizer) would not show different patterning for the old-same class items, but they would be distinguished once we take three word conditions (old-same class, new-same class, new-gen) into account. For the purpose of clearness, I illustrate one word condition at a time, starting from old-same class items.
} 
Generalizer means that participants not only learn the pattern, but also succeed in generalizing from an old target to a new test consonant. Like the pattern learners, they would also favor grammatical old-same class items $(1,2,3,4)$ over ungrammatical items (1', 2', 3', 4') (cf. Table 3 and Table 4).

Generalizer (opposite) means that participants learn the pattern and could be able to generalize to a new consonant. However, they make a generalization in an opposite way: treating a new test consonant as a blocker instead of a target. Again, they would tend to choose grammatical old-same class $(1,2,3,4)$ than ungrammatical old-same class items (1', 2', 3', 4') (cf. Table 3 and Table 4).

Statistician means that participants use statistical knowledge such as phonotactics to make their decision. For instance, they might make an assumption that whenever the second syllable with a target is nasalized, it should be counted as "correct"4 Such participants would favor a second syllable being nasalized with a target. Consider Pattern $1 \mathrm{~S}(\mathrm{k}) \rightarrow \mathrm{W}(\mathrm{k})$ for instance (see Table 3). Participants would judge as grammatical, for

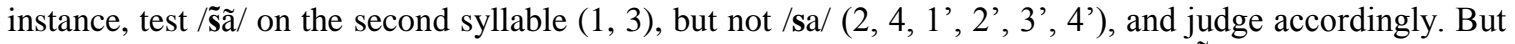
they would have no idea about how to choose between the pair (2) /ãkasa/ and (2') /ã $\tilde{k} a \mathbf{s a} /$ since target /s/ is not in the second syllable.

Pluralizer means participants misinterpret that nasalization equals plurality (i.e., morphological learner, nasalization $=$ plurality). The more syllables that get nasalized within a word, the better the word is. They calculated the number of nasalized syllables and always favor a word with larger number of nasalized syllables over a word with smaller number of nasalized syllables. That is, a word with three nasalized syllables would be chosen over one with one or two nasalized syllable $\left(5,7,8,6^{\prime}, 9^{\prime}\right)$. Consider Pattern 2 $\mathrm{W}(\mathrm{k}) \rightarrow \mathrm{S}(\mathrm{k})$ for instance (see Table 4). Participants would favor grammatical (1) /ã $\tilde{\mathbf{w} a ̃ k}$ / over ungrammatical (1') /ãwaka/ because (1) has two nasalized syllables, while (1') only has one nasalized. However, they would favor ungrammatical (2') /ã kãa/ over grammatical (2) /ãkawa/ since the former's number of nasalized syllables is larger than the latter.

4.2.2 New-same class (different vowel) Now I turn to the predictions of new-same class items for Pattern 1 in Table 5 and for Pattern 2 in Table 6. Being able to learn the new-same class items suggests that participants learned the pattern since they could apply rules to a "new" vowel, not simply memorizing old items.

Table 5. Pattern 1: Predictions of raw responses for test items by leaners' types: new-same class

\begin{tabular}{|c|c|c|c|c|c|c|}
\hline & \multicolumn{6}{|c|}{ Pattern 1: $\mathbf{S}(\mathbf{k}) \rightarrow \mathbf{W}(\mathbf{k})$} \\
\hline & & \multicolumn{3}{|c|}{ categorization learner } & \multicolumn{2}{|c|}{ statistical learner } \\
\hline & & $\begin{array}{l}\text { pattern } \\
\text { learner }\end{array}$ & generalizer & $\begin{array}{c}\text { generalizer } \\
\text { (opposite) }\end{array}$ & statistician & pluralizer \\
\hline & New-same class & & & & & \\
\hline \multirow[t]{5}{*}{ grammatical } & (5) /ãs̃̃̃a/ & $\checkmark$ & $\checkmark$ & $\checkmark$ & $\checkmark$ & $\checkmark$ \\
\hline & (6) /ãkase/ & $\checkmark$ & $\checkmark$ & $\checkmark$ & & \\
\hline & (7) /ã̃̃ãke/ & $\checkmark$ & $\checkmark$ & $\checkmark$ & $\checkmark$ & $\checkmark$ \\
\hline & (8) /ã̃̃ $\tilde{\mathbf{s}} \tilde{\mathbf{s}} /$ & $\checkmark$ & $\checkmark$ & $\checkmark$ & $\checkmark$ & $\checkmark$ \\
\hline & (9) /ãkesa/ & $\checkmark$ & $\checkmark$ & $\checkmark$ & & \\
\hline \multirow[t]{5}{*}{ ungrammatical } & (5')/ãseka/ & & & & & \\
\hline & (6') /ãkãse/ & & & & & $\checkmark$ \\
\hline & (7’) /ãsake/ & & & & & \\
\hline & (8') /ãsese/ & & & & & \\
\hline & (9’)/ã̃ẽsa/ & & & & & $\checkmark$ \\
\hline
\end{tabular}

${ }^{4}$ The second syllable being nasalized is just one kind of strategy used by statisticians. Participants could use other kinds of statistical learning to make a judgment. 
Table 6. Pattern 2: Predictions of raw responses for test items by leaners' types: new-same class

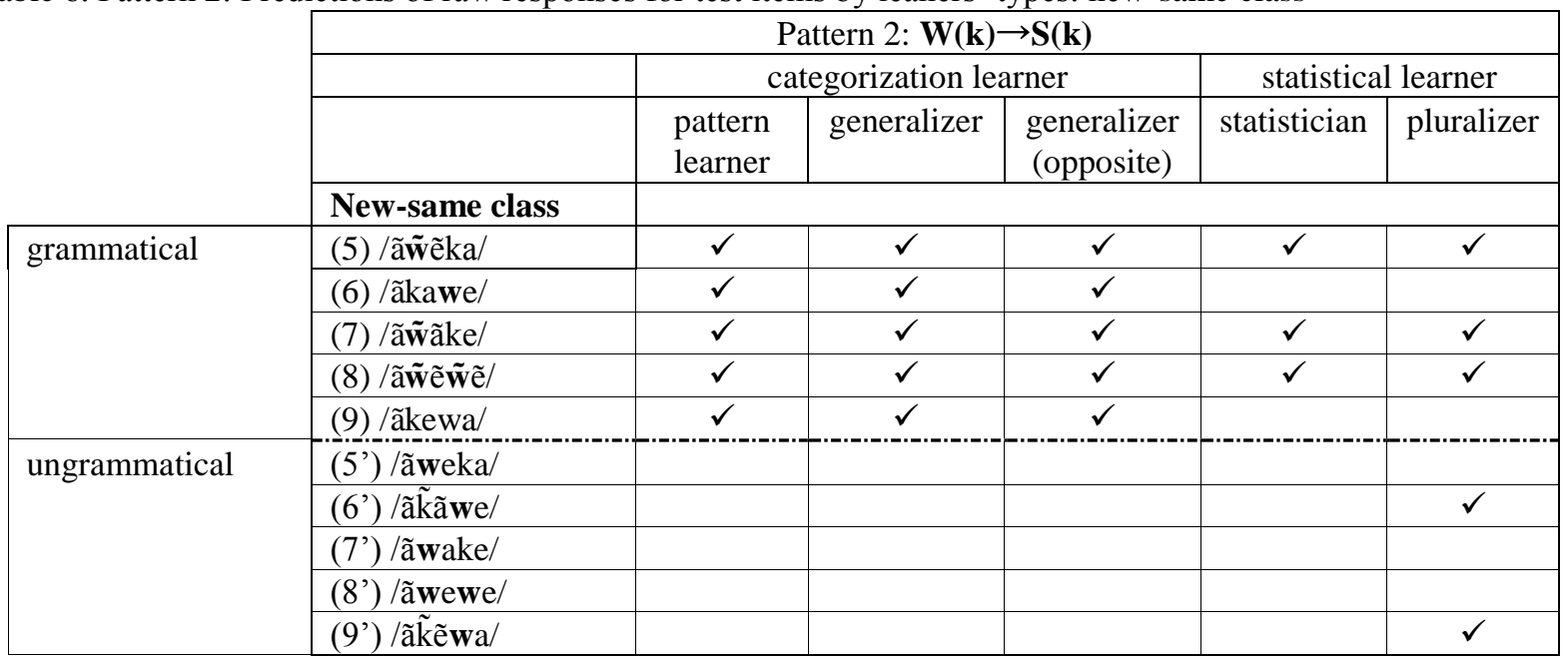

Recall that for pattern learner, generalizer, and generalizer (opposite), they all learned the pattern. I would expect that participants for these three learner's types would tend to favor grammatical new-same class over ungrammatical ones (cf. Table 5 and Table 6). This suggest that participants would be able to apply the rules conditioning plural change on new vowels.

Recall that statistician means that participants use statistical knowledge to make their decision (e.g., second syllable being nasalized).

Recall that pluralizer means participants misinterpret that nasalization equals plurality (i.e., morphological learner, nasalization = plurality, the more nasalized syllables a word has, the better).

4.2.3 New-gen class (different consonant) Now I turn to the predictions of new-gen class items for Pattern 1 in Table 7 and for Pattern 2 in Table 8. This one is important since it differentiates the sub-types of categorization learners.

Table 7. Pattern 1: Predictions of raw responses for test items by leaners' types: new-gen

\begin{tabular}{|c|c|c|c|c|c|c|}
\hline & \multicolumn{6}{|c|}{ Pattern 1: $\mathbf{S}(\mathbf{k}) \rightarrow \mathbf{W}(\mathbf{k})$} \\
\hline & & \multicolumn{3}{|c|}{ categorization learner } & \multicolumn{2}{|c|}{ statistical learner } \\
\hline & & $\begin{array}{l}\text { pattern } \\
\text { learner }\end{array}$ & generalizer & $\begin{array}{c}\text { generalizer } \\
\text { (opposite) }\end{array}$ & statistician & pluralizer \\
\hline & New-gen & & & & & \\
\hline \multirow[t]{5}{*}{ grammatical } & (10) /ãwããa/ & & $\checkmark$ & & & $\checkmark$ \\
\hline & (11) /ãkawa/ & & $\checkmark$ & & & \\
\hline & (12) /ã̃̃ã̃̃ã/ & & $\checkmark$ & & & $\checkmark$ \\
\hline & 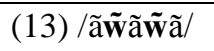 & & $\checkmark$ & & & $\checkmark$ \\
\hline & (14) /ã̃̃ã)̃̃a/ & & $\checkmark$ & & $(\checkmark)$ & $\checkmark$ \\
\hline \multirow[t]{5}{*}{ ungrammatical } & (10’)/ãwaka/ & & & $\checkmark$ & & \\
\hline & $\left(11^{\prime}\right) / \tilde{a} \tilde{k} \tilde{a} \tilde{w} \tilde{a} /$ & & & $\checkmark$ & & $\checkmark$ \\
\hline & (12') /ãwasa/ & & & $\checkmark$ & & \\
\hline & (13’)/ãwawa/ & & & $\checkmark$ & & \\
\hline & (14') /ã̃̃ãwa/ & & & $\checkmark$ & $(\checkmark)$ & \\
\hline
\end{tabular}


Table 8. Pattern 2: Predictions of raw responses for test items by leaners' types: new-gen

\begin{tabular}{|c|c|c|c|c|c|c|}
\hline & \multicolumn{6}{|c|}{ Pattern 2: $\mathbf{W}(\mathbf{k}) \rightarrow \mathbf{S}(\mathbf{k})$} \\
\hline & & \multicolumn{3}{|c|}{ categorization learner } & \multicolumn{2}{|c|}{ statistical learner } \\
\hline & & $\begin{array}{l}\text { pattern } \\
\text { learner }\end{array}$ & generalizer & $\begin{array}{c}\text { generalizer } \\
\text { (opposite) }\end{array}$ & statistician & pluralizer \\
\hline & New-gen & & & & & \\
\hline \multirow[t]{5}{*}{ grammatical } & (10) /ã̃̃ãka/ & & $\checkmark$ & & & $\checkmark$ \\
\hline & (11) /ãkasa/ & & $\checkmark$ & & & \\
\hline & (12) /ã̃̃ã $\tilde{\mathbf{w a}} /$ & & $\checkmark$ & & & $\checkmark$ \\
\hline & (13) /ã̃̃ã)̃̃̃ / & & $\checkmark$ & & & $\checkmark$ \\
\hline & (14) /ãwãã̃̃a// & & $\checkmark$ & & $(\sqrt{ })$ & $\checkmark$ \\
\hline \multirow[t]{5}{*}{ ungrammatical } & $\left(10^{\prime}\right) / a ̃ s a k a /$ & & & $\checkmark$ & & \\
\hline & (11’) /ã̃ $\tilde{a} \tilde{\mathbf{s} a} /$ & & & $\checkmark$ & & $\checkmark$ \\
\hline & (12’) /ãsawa/ & & & $\checkmark$ & & \\
\hline & (13’) /ãsasa/ & & & $\checkmark$ & & \\
\hline & (14') /ã̃̃̃ãsa/ & & & $\checkmark$ & $(\checkmark)$ & \\
\hline
\end{tabular}

Only generalizers and opposite generalizers could generalize to a new consonant. Specifically, a generalizer patterns an old target with a new test consonant and treats a new test consonant as a target, meaning that they would tend to favor grammatical new-gen over ungrammatical items (see Table 7 and Table 8). An opposite generalizer makes a generalization in the opposite way: treating a new test consonant as a blocker instead of a target. Since they treat a new consonant as a blocker, it is expected that they would be inclined to favor ungrammatical new-gen items over grammatical ones (see Table 7 and Table 8).

For new-gen items, statistician would have difficulty in choosing one from a particular pair: (14) /ãs̃ã $\tilde{\text { ã/ }}$ vs. (14') /ã̃̃ãwa/ (Pattern 1), and (14) /ã̃̃ã̃̃ã/ vs. (14') /ã̃̃ãa/ (Pattern 2) because in both words, a second syllable with a target is nasalized. This is why I put a check mark in brackets $(\checkmark)$.

4.3 Individual results Table 9 summarizes the distribution of participant types by subcategories (i.e., learner, generalizer, generalizer (opposite), statistician, pluralizer, and "random" for Patterns $1(\mathrm{~S}(\mathrm{k}) \rightarrow \mathrm{W}(\mathrm{k}))$ and $2(\mathrm{~W}(\mathrm{k}) \rightarrow \mathrm{S}(\mathrm{k}))$. For instance, in Pattern $1(\mathrm{~S}(\mathrm{k}) \rightarrow \mathrm{W}(\mathrm{k})), 1$ participant belongs to learner, 3 belong to generalizer, 2 belong to generalizer (opposite), 2 belong to statistician, 1 belongs to pluralizer, and 1 belongs to random. I focus on the results for the categorization learners.

Table 9. Pattern 1: SW vs. Pattern 2: WS (Individual difference)

\begin{tabular}{|c|c|c|c|c|c|}
\hline \multicolumn{3}{|c|}{ Pattern 1: $\mathrm{S}(\mathrm{k}) \rightarrow \mathrm{W}(\mathrm{k})$} & \multicolumn{3}{|c|}{ Pattern 2: $\mathrm{W}(\mathrm{k}) \rightarrow \mathrm{S}(\mathrm{k})$} \\
\hline & exposure & test & & exposure & test \\
\hline $\mathrm{k}$ as blocker & $\mathrm{s}$ as target & w as target & $\mathrm{k}$ as blocker & $\mathrm{w}$ as target & $s$ as target \\
\hline learner & $\mathrm{n}=1$ & & & $\mathrm{n}=0$ & \\
\hline generalizer & $\mathrm{n}=3$ & & & $\mathrm{n}=2$ & \\
\hline generalizer (opposite) & $\mathrm{n}=2$ & & & $n=6$ & \\
\hline statistician & $\mathrm{n}=2$ & & & $\mathrm{n}=2$ & \\
\hline pluralizer & $\mathrm{n}=1$ & & & $\mathrm{n}=0$ & \\
\hline random & $\mathrm{n}=1$ & & & $\mathrm{n}=0$ & \\
\hline
\end{tabular}

It seems that both Patterns 1 and 2 had roughly the same number of learners (categorization learning: learner, generalizer, generalizer (opposite), but the difference between these two is that Pattern 2 had more opposite generalizers than Pattern 1 did, which means that participants for Pattern 2 participants treated a new consonant /s/ as a blocker rather than a target.

What does that suggest? The first possibility (implicational universals) is that it suggests treating a new consonant /s/ as a target is a harder pattern to learn/generalize (compared to $/ \mathrm{s} / \mathrm{as}$ a target $\rightarrow / \mathrm{w} /$ ), so that participants had difficulty in generalizing from an old consonant /w/ as a target to /s/. If so, it would support my hypothesis of implicational universals on nasalized segment scale. 
The second possibility (patterning) is that it suggests that even though Min does not have any obvious sonority effects, for WS pattern, Min speakers were still able to try to pattern $/ \mathrm{k} /$ as a blocker with $/ \mathrm{s} /$, since both $/ \mathrm{k} /$ and $/ \mathrm{s} /$ belong to obstruents. That's why $\mathrm{W}(\mathrm{k}) \rightarrow \mathrm{S}(\mathrm{k})$ had more opposite generalizers (i.e., treating /s/ as a blocker instead of target).

It seems that the second possibility is more plausible. For the $\mathrm{S}(\mathrm{k}) \rightarrow \mathrm{W}(\mathrm{k})$ pattern, few participants generalized from $/ \mathrm{s} /$ as a target to $/ \mathrm{w} /$ as a target, which poses a challenge to the first possibility that $\mathrm{W}(\mathrm{k}) \rightarrow \mathrm{S}(\mathrm{k})$ is harder to learn/generalize than $\mathrm{S}(\mathrm{k}) \rightarrow \mathrm{W}(\mathrm{k})$. Maybe the reason why few participants made a generalization is because participants thought that $/ \mathrm{s} /$ and $/ \mathrm{w} /$ do not belong to the same phonological class, so that they tended not to treat a new consonant $/ \mathrm{w} /$ as a target. They also failed to pattern $/ \mathrm{k} /$ as a blocker with $/ \mathrm{w} /$, because $/ \mathrm{k} /$ and $/ \mathrm{w} /$ do not belong to the same phonological class. In brief, the current individual results seem to suggest that instead of directionality of implicational universals, participants were trying to compare whether a new segment's phonological class is close to any old segment's phonological class. If yes, then participants pattern the two segments together, assigned the same status of nasality function (i.e, target or blocker) (i.e., among old and new segments, there is reference to natural classes).

Table 10 summarizes the distribution of participant types by subcategories except for "random" for Patterns 3 and 4. For instance, in Pattern 3, 2 participant belongs to "learner", 4 belongs to "generalizer", and so forth. In general, the major difference between the two patterns is that Pattern 4: $k(W) \rightarrow t(W)$ seems to have more generalizers than Pattern 3: $\mathrm{k}(\mathrm{S}) \rightarrow \mathrm{t}(\mathrm{S})$. What does that imply? I discuss this question following the table.

Table 10. Pattern 3: $\mathrm{k}(\mathrm{S}) \rightarrow \mathrm{t}(\mathrm{S})$ vs. Pattern 4: $\mathrm{k}(\mathrm{W}) \rightarrow \mathrm{t}(\mathrm{W})$ (Individual difference)

\begin{tabular}{|c|c|c|c|c|c|}
\hline \multirow[b]{2}{*}{$\mathrm{k}(\mathrm{W}) \rightarrow \mathrm{t}(\mathrm{W})$} & \multicolumn{4}{|c|}{ Pattern 3: $\mathrm{k}(\mathrm{S}) \rightarrow \mathrm{t}(\mathrm{S})$} & \multirow[t]{2}{*}{ Pattern 4: } \\
\hline & & & & & \\
\hline & exposure & test & & exposure & test \\
\hline $\mathrm{s}$ as target & $\mathrm{k}$ as blocker & $\mathrm{t}$ as blocker & w as target & $\mathrm{k}$ as blocker & $\mathrm{t}$ as blocker \\
\hline learner & $\mathrm{n}=2$ & & & $\mathrm{n}=0$ & \\
\hline generalizer & $\mathrm{n}=4$ & & & $\mathrm{n}=9$ & \\
\hline generalizer (opposite) & $\mathrm{n}=1$ & & & $\mathrm{n}=1$ & \\
\hline statistician & $\mathrm{n}=3$ & & & $\mathrm{n}=0$ & \\
\hline pluralizer & $\mathrm{n}=0$ & & & $\mathrm{n}=0$ & \\
\hline random & $\mathrm{n}=0$ & & & $\mathrm{n}=0$ & \\
\hline
\end{tabular}

The hypothesis about reference to natural classes is also applicable to the follow-up experiments, Patterns 3 and 4: $\mathrm{k}(\mathrm{S}) \rightarrow \mathrm{t}(\mathrm{S})$ vs. $\mathrm{k}(\mathrm{W}) \rightarrow \mathrm{t}(\mathrm{W})$. The individual results show that $\mathrm{k}(\mathrm{S}) \rightarrow \mathrm{t}(\mathrm{S})$ has 4 generalizers, while $\mathrm{kt}$ $\mathrm{W}$ has 9 generalizers. These results support the hypothesis that predicts that if participants pattern a new segment depending on phonological classes of old segments (that is, taking both old target and blocker into account-reference to natural classes), then it is expected that $\mathrm{k}(\mathrm{S}) \rightarrow \mathrm{t}(\mathrm{S})$ might be harder to learn than $\mathrm{k}(\mathrm{W}) \rightarrow \mathrm{t}(\mathrm{W})$, since the sonority distance between $/ \mathrm{s} /$ and a new segment $/ \mathrm{t} /$ is shorter than that between $/ \mathrm{w} /$ and $/ \mathrm{t} /$. Specifically, for Pattern 3: $\mathrm{k}(\mathrm{S}) \rightarrow \mathrm{t}(\mathrm{S})$, though $/ \mathrm{k} /$ and $/ \mathrm{t} /$ belong to the same phonological class, stop, the fact that $/ \mathrm{s} /$ is a fricative might create difficulty for participants to determine whether $/ \mathrm{t} /$ should pattern with $/ \mathrm{k} /$ as a blocker or with $/ \mathrm{s} /$ as a target (i.e., $/ \mathrm{t}, \mathrm{k}, \mathrm{s} /$ belong to obstruents). On the contrary, for Pattern 4 : $\mathrm{k}(\mathrm{W}) \rightarrow \mathrm{t}(\mathrm{W})$, the distance between $/ \mathrm{w} /$ and $/ \mathrm{t} /$ on the hierarchy is further, which makes it easier for participants to pattern a new segment $/ \mathrm{t} /$ with $/ \mathrm{k} /$ as a blocker.

\section{General discussion}

Categorization learners (individual results) appear at first to focus more on natural classes: for instance, with exposure to $/ \mathrm{k} /$ and $/ \mathrm{w} /$, they group $/ \mathrm{k} /$ and test segment $/ \mathrm{s} /$ together as well as $/ \mathrm{k} /$ and test segment $/ \mathrm{t} /$ together. In general then, the categorization learners appeared to be comparing whether a new segment's natural class is closer to an old segment's natural class, and pattern the new segment with that old one. Based on descriptive statistical findings, direction did not seem to matter with the categorization learners: it appeared from these statistics that they were simply creating natural classes.

However, the group results tell a different story: they show a positive influence of direction for both 
groups (Patterns 1,2) of categorization learners, with testing on a more sonorant segment than learners were exposed to (Pattern 1) being better learned than testing on a less sonorant segment (Pattern 2). The group results suggest that a hierarchy (nasalized segment scale) matters to categorization learners.

\section{Conclusion}

In sum, the current study is a new kind of paradigm to investigate with the Artificial Grammar paradigm - most of the work in this area tests natural classes, while this study examines the relationship between natural classes as well. Individual results and group results show evidence that both natural classes (new segment is of the same natural class as the blocker) and a hierarchy play an important role in learning for the categorization learners.

\section{References}

Albright, Adam \& Young Ah Do. (2013). Biased learning of phonological alternations. The $21^{\text {th }}$ Manchester Phonology Meeting, May 23-25, Manchester, UK.

Bates, Douglas \& Martin Maechler. (2009). lme4: Linear mixed-effects models using S4 classes. R package version 0.999375-32. http://CRAN.R-project.org/package=lme4

Blevins, Juliette. (1995). The syllable in phonological theory. In John Goldsmith (ed.). Handbook of phonological theory. Blackwell. 206-244.

Blevins, Juliette. (2004). Evolutionary phonology. Cambridge University Press.

Blevins, Juliette. (2006). A theoretical synopsis of evolutionary phonology. Theoretical Linguistics 32. 117-165.

Botma, Bert. (2011). Sororants. (2011). The representation of fricatives. In Marc van Oostendorp, Colin J. Ewen, Elizabeth Hume, and Keren Rice (eds.). The Blackwell Companion to Phonology. Oxford: Wiley-Blackwell. 171-94.

Clement, George N. (1990). The role of the sonority cycle in core syllabification. In John Kingston, and Mary Beckman (eds.) Papers in Laboratory Phonology: Between the Grammar and Physics of Speech. Cambridge: Cambridge University Press. 1838-1865.

Cser, András. (2003). The typology and modelling of obstruent lenition and fortition processes. Budapest: Akadémiai Kiadó.

Daland, Robert, Bruce Hayes, James White, Marc Garellek, Andrea Davis \& Ingrid Norrmann. (2011). Explaining sonority projection effect. Phonology 28. 197-234.

de Lacy, Paul. (2000). Markedness in prominent positions. In Ora Matushansky, Albert Costa, Javier Martin-Gonzalez, Lance Nathan, and Adam Szczegielniak (eds.) HUMIT 2000, MIT Working Papers in Linguistics 40. Cambridge, MA: MITWPL. 53-66.

de Lacy, Paul. (2006). Markedness: Reduction and Preservation in Phonology. Cambridge Studies in Linguistics 112. Cambridge University Press.

Evans \& Levinson. (2009). The myth of language universals: Language diversity and its importance for cognitive science. Behavioral and Brain Science 32. 429-492.

Finley, Sara. (2011). The privileged status of locality in consonant harmony. Journal of Memory and Language 65. $74-$ 83.

Fiser, József \& Aslin, Richard N. (2002). Statistical learning of new visual feature combinations by infants. Proceedings of the National Academy of Sciences 99, 15822-15826.

Gomez, Rebecca L. \& LouAnn Gerken. (1999). Artificial grammar learning by 1-year-olds leads to specific and abstract knowledge. Cognition 70. 109-135.

Gordon, Mathew. (1999). Syllable weight: Phonetics, phonology and typology. Doctoral dissertation, UCLA.

Henke, Eric, Ellen M. Kaisse \& Richard Wright. (2012). Is the Sonority Sequencing Principle an epiphenomenon? In Steven Parker (ed.), The sonority controversy. (Phonology and Phonetics 18). Berlin/Boston: De Gruyter Mouton. 65-100.

Honeybone, Patrick. (2008). Lenition, weakening and consonantal strength: Tracing concepts through the history of phonology. In Brandão de Carvalho, J., Scheer, T. \& Ségéral, P. (eds). Lenition and Fortition. Berlin: Mouton de Gruyter. 9-93.

Hooper, Joan B. (1976). Word frequency in lexical diffusion and the source of morphophonological change. In William M. Christie (ed.). Current progress in historical linguistics. Amsterdam: North Holland. 96-105.

Kapatsinski, Vsevolod. (2009). The architecture of grammar in artificial grammar learning: formal biases in the acquisition of morphophonology and the nature of the learning task. Doctoral dissertation, Indiana University. 
Lin, Yu-Leng. (2010). Testing Universal Grammar in phonological artificial grammar learning. Master thesis. National Chung Cheng University, Taiwan.

Mielke, Jeff. (2011). Distinctive Features. In Marc van Oostendorp, Colin Ewen, Elizabeth Hume, and Keren Rice (eds.). Companion to Phonology. Wiley-Blackwell. 391-415.

Moreton, Elliott \& Joe Pater (2012 a). Structure and Substance in Artificial-Phonology Learning, Part I: Structure. Language and Linguistics Compact. 686-701.

Moreton, Elliott \& Joe Pater (2012 b). Structure and Substance in Artificial-Phonology Learning, Part I: Substance. Language and Linguistics Compact. 702-718.

Moreton, Elliott. (2008). Analytic bias and phonological typology. Phonology 25(1). 83-127.

Nevins, Andrew. (2010). Two case studies in phonological universals: A view from artificial grammars. Biolinguistics 4. 217-232.

Parker, Steve. (2002). Quantifying the sonority hierarchy. Doctoral dissertation, University of Massachusetts, Amherst.

Parker, Steve. (2008). Sound level protrusions as physical correlates of sonority. Journal of Phonetics 36. 55-90.

Parker, Steve. (2011). Sonority. In Marc van Oostendorp, Colin J. Ewen, Elizabeth Hume, and Keren Rice (eds.). The Blackwell Companion to Phonology. Oxford: Wiley-Blackwell. 1160-1184.

Pierrehumbert, Janet B. (2002). An Unnatural Process. The $8^{\text {th }}$ Meeting on Laboratory Phonology.

Prince, Alan \& Paul Smolensky. (1993). Optimality Theory: Constraint interaction in generative grammar. Rutgers Technical Report TR-2. New Brunswick, NJ, Rutgers Center for Cognitive Science [also Rutgers Optimality Archive 537]. Published in 2004 by Blackwell

Saffran, Jenny R. Elizabeth Johnson K., Richard Aslin N. \& Elissa Newport L. (1999). Statistical learning of tone sequences by human infants and adults. Cognition 70. 27-52.

Saffran, Jenny R., Richard Aslin N. \& Elissa Newport L. (1996). Statistical learning by 8-month-old infants. Science 274. 1926-1928.

Smith, Jennifer. (2002). Phonological augmentation in prominent positions. Doctoral dissertation, University of Massachusetts, Amherst.

Walker, Rachel. (2000). Nasalization, neutral segments and opacity Effects. New York: Garland.

Walker, Rachel. (2011). Nasal harmony. In Marc van Oostendorp, Colin Ewen, Elizabeth Hume \& Keren Rice (eds.) The Blackwell Companion to Phonology. Oxford: Wiley-Blackwell. 1838-1865.

Wilson, Colin. (2006). Experimental investigation of phonological naturalness. WCCFL 22. 533-546.

Yang, Charles. (2004). Universal grammar, statistics, or both. Trends in Cognitive Sciences 8, 451-456.

Zec, Draga. (2007). The syllable. In Paul deLacy (ed,), The Cambridge Handbook of Phonology. Cambridge: Cambridge University Press. 161-193. 